\title{
Row-by-Column, Plexiglass \& Zoom, Oh My! A K-12 COVID-19 Storm / A Pilot
}

\author{
Lennie Scott-Webber ${ }^{1}$ \\ ${ }^{1}$ INSYNC; Education Research + Design [Independent Researcher], Estero, Florida, USA \\ Correspondence: Lennie Scott-Webber, INSYNC; Education Research + Design [Independent Researcher], \\ Estero, Florida, USA. E-mail: lenniesw.insync@yahoo.com
}

Received: December 29, 2020 Accepted: January 30, 2021 Online Published: February 3, 2021

doi:10.5539/jel.v10n2p9 URL: https://doi.org/10.5539/jel.v10n2p9

\begin{abstract}
We are 21 years into the 21 st century, and educational practices across North America were woefully unprepared to 'flip the switch' to online learning; at times no education occurred at all, not online or onsite. The COVID-19 pandemic disruptor storm peeled off the layers of blindfolds time accrued in an instant. Issues included three areas. Area one - unpreparedness: digital illiteracy relative to online learning and corresponding teaching models, equity issues pertaining to internet access and computer access, platforms that varied and were unreliable. Area two-inconsistent: (if any) guidelines on how to teach onsite, or those from a disease control group dictating a six-foot distancing, masks, plexiglass, and row-by-column with eyes facing forward (back to a 19th century teaching didactic model), and smaller class sizes. Area three-time/space continuum: the combining of online and onsite, teaching loads, and maintenance. This 'alpha' research study tried to capture a historic moment in time. A Human-centered Research Design (HcRD) protocol with three techniques to mitigate bias was used: (1) online survey, (2) focused interviews, and (3) crowd-sourced photographic content across two countries-USA and Canada as a convenience sample. The findings will reveal a 'just-in-time' snap shot of the tactics used pre- and current-, as well as ideas for post-pandemic - this research's differentiator. The storm of COVID-19 played unprecedented havoc on schools across North America, but there are important learnings and these, along with some insights will be shared.
\end{abstract}

Keywords: COVID-19, engagement, design, innovation, K-12 education, online, time/space

\section{Introduction}

\subsection{Introduction to the Problem}

The research contributes to building knowledge by documenting from the educators' perspectives the current situation (during the COVID-19 storm which first began in March 2020), the just-in-time innovations made, documented lessons learned, and what this time might yield for future learning experiences. The research took place in fall of 2020, to ensure a more 'normalized' scenario was in situ. This response was smaller than hoped, but some important discoveries that will benefit educational leadership, educators, students, parents, online learning, and the design community are shared. The theme here is to understand from the teachers' perspective, how learning was experienced and what it looked like physically from a Time/Space Continuum (Scott-Webber, 2020a), and how teachers were coping.

COVID-19 turned the world of education, learning and teaching upside down - a clear disruptor (Christensen, 1997; Christensen \& Raynor, 2003; Kelley \& Littman, 2001). Thus, it was deemed important to try and capture this historic period of time from the educators practicing in kindergarten through grade $12(\mathrm{~K}-12)$. The focused geography was North America (USA and Canada) due to the opportunity of a convenience sample. This study relates to previous work done in the area of student engagement and learning, and how the design of the built space impacts student engagement levels (Scott-Webber, Konyndyk, \& Denison, 2019; Scott-Webber, Konyndyk, \& French, 2019; Scott-Webber, Konyndyk, French, \& French, 2018). As mentioned, it was conducted in fall of 2020, and used educators as learning experts. This research study was conducted to, "Hear the voices of educators relative to how the design of learning experiences, and places were at the current moment (in-pandemic), and how these might be thought of in a post-pandemic world; in the K-12 arena."

Its foci were to: (1) understand how educators were adjusting to these new, sometimes daily demands, (2) 
determine what the current classroom situation actually looked like, what was different/same across the time/space continuum, (3) generate an opportunity seven months into the pandemic for teachers to share how they might envision a future learning experience based on lessons-learned, and (4) provide them with a voice on how collegial collaboration was working pre-, current-, and post-pandemic.

This study used a Human-centered Research Design (HcRD) (Scott-Webber, Konyndyk, \& Denison, 2019) as a mixed-method protocol with three techniques and three situations studied. The techniques included: (a) online survey, (b) focused interviews, and (c) crowd-sourced photo images and writings. The situational scenarios included: (a) online, (b) onsite, and (c) a new hybrid/both online and onsite. The HcRD design engaged multiple members of the education community across two countries using a convenience sample to build a 'picture' of what teaching and learning in this historic situation 'felt' like from a teaching perspective. as well as what it actually 'looked like,' and what the future might hold.

Reading this article, you will:

- see the connections between historical teaching methods and the disruption of COVID-19;

- realize education's challenges to meet 21 st century technologically-enabled learning needs;

- be provided with a rich set of examples from multiple data gathering techniques;

- know that the design of learning experience is connected to both time and space; and

- recognize that lessons learned did not embrace dramatic change for post-pandemic; and

\subsection{Overview of Main Sections}

This paper has 5 areas of interest. In Area 1 (i.e., 1.3), the problem is explored relative to what this research was trying to uncover. In Area 2 (i.e., 1.4), the relevant background supporting this work is shared. Area 3 is Methods (i.e., 2), with Area 4 providing the Results which include information from each of the techniques used to gather data. Area 5, brings the article to a Conclusion (i.e., 3).

\subsection{Area \#1-Explore the Problem}

This problem deserved new research as the world entered an unprecedented time frame with COVID-19 as a global pandemic. It is argued here that this research builds upon past work relative to teaching and learning engagement factors, and in particular how the built environment impacts student engagement in the learning process. This situation was new; a new social situation was unfolding in the educational arena. A snap shot of 'in the moment' was deemed important.

21 years into the 21 st century and yet education was clearly unprepared to 'flip the switch' to online learning. Corporations around the world did, yet education could not. Why? Across headlines, news releases, and multiple documents the storm of COVID-19 left educational entities feeling directionless. In the early months of the pandemic, districts simply closed schools immediately and sent everyone home. Period. No school. No classes, and no idea of when school might start up again. Parents, students, and teachers were at a lost as to what would come next. During these early closures, districts quickly tried to understand how they might reboot and move to online learning, or prepare classes for a very different onsite experience, or both-a Time/Space Continuum (Scott-Webber, 2020a) conundrum. The challenges were many, and other than those from the disease control centers (particularly relevant to the USA), no consistent directions were provided as to how to set up for this new world. Clearly, there was a disruption. Problems began to be identified. A few are listed here, but all revolve around how to get the content to the student:

- Online:

- Lack of preparation from educators that could easily move his/her content to online learning (Zoom was the most used tool)

- Clear digital divide between educators and online learning as well as students

- No internet, or no consistent internet connection

- No computer, or not enough to share with siblings

$\circ$ Inconsistencies with hardware and software.

- Onsite

- Size of classes made smaller

- Row-by-column situations reset to 19th century delivery methods and practices 
- Tape areas to guard areas by user type

- Plexiglass shields

$\circ$ Facing forward.

- New Hybrid/Both

- Simultaneous - broadcast and onsite

- Shifts in days online versus onsite - a new hybrid.

This research study tried to capture this point in time (fall 2020 as the new rhythm, COVID-19 response, was more established than in the first few months) for several reasons to: (1) understand how educators were adjusting to these new, sometimes daily demands, (2) determine what the current classroom situation actually looked like, what was different/same, (3) generate an opportunity seven months into the pandemic for teachers to share how they might envision a future learning experience based on lessons-learned, and (4) provide them with a voice on how collegial collaboration was working pre-, current-, and post-pandemic. A background of research is shared next and begins to 'set the stage.'

This current work builds on a career effort and the questions used are framed from multiple researchers in several domains (Scott-Webber, 1999, 2000b), particularly classical Environment Behavior Theorists in an effort to examine space and its relationship to its users. The design of the built environment makes a difference in the way users behave. Some classic EB researchers include: Hall (1966), Sommer (1959), Maslow (1943), Anderson and Krathwohol (2001), Elliot and Covington (2001), Scott-Webber (2000b \& 2004), Scott-Webber, Abraham and Marini (2000). Early research work from this author was completed in higher education (Scott-Webber, 2014; Scott-Webber, Strickland, \& Kapitula, 2013; Scott-Webber Marini, \& Abraham, Spring, 2000), and newer research in grades kindergarten to grade 12 (French, Scott-Webber \& Sivakumar, 2020; Kilbourne, Scott-Webber, \& Kapitula, 2017; Scott-Webber, Konyndyk, \& Denison, 2019; Scott-Webber, Konyndyk, \& French, 2019; Scott-Webber, Konyndyk, French, \& French, 2018; Scott-Webber, Konyndyk, French, Lembke, \& Kinney, 2017).

\subsection{Relevant Scholarship}

Educating is not easy. Unlike most educators who teach in higher education, pre-K-12 teachers are taught how to teach which include theories of teaching and learning, educational psychology theories, and the multiple ways in which learners must take in content to prepare them to teach. They earn their 'teaching stripes' through first receiving a bachelor's degree, then most often a masters, and some earn an Ed.D. Some specialize either in content or grade level.

For decades education has been delivered by content experts (e.g., teachers/faculty). The delivery method by in large has been the Instructivist Method-didactic/lecture (Skinner, 1974; Merrill, 2002; Carrol, 1963). This method is opposite of an active learning experience and is considered a passive one (i.e., "Knowledge is transferred to the student. The responsibility for learning using this method is with the instructor"; Oregon State, n.d.). The design of the built space supported this delivery method and is often referred to as Henry Ford's 'factory model' (see Figure 1) with row-by-column seating for students all facing forward, and the teacher at the front lecturing (Scott-Webber, 2004) at the 'micro level' or classroom-this research's focus. The overall building designs, or 'macro level' was called a 'double-loaded' corridor with two rows of classrooms separated by a large hallway or corridor. 


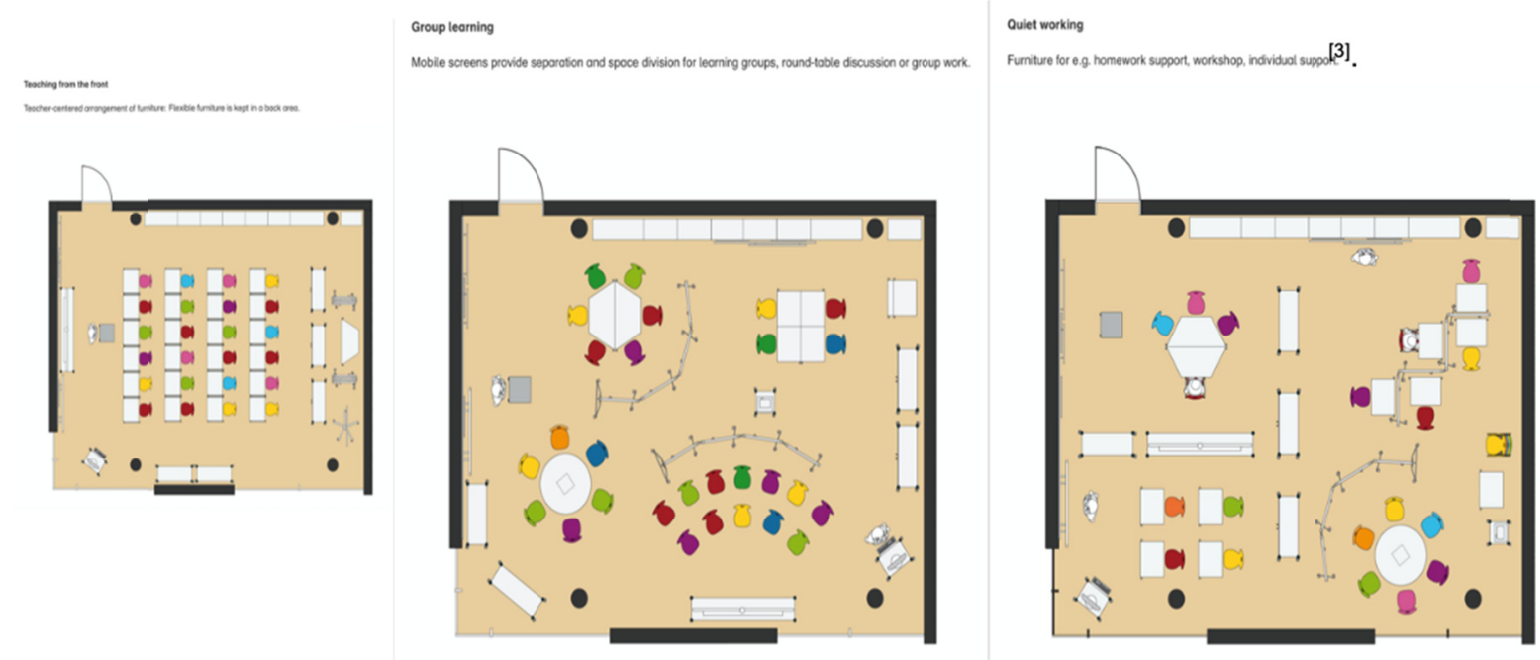

Figure 1. Classroom designs - 1 traditional passive design to 2 new active classroom design arrangement examples (with permission of VS America, Inc.; Scott-Webber, 2020a).

It has also been recognized that passive learning is perhaps not the best way to actually learn. A more active approach is deemed necessary for the learner to actually 'own' their own knowledge; actively engage in one's learning process is a high predictor of scholarly achievement (NSSE, 2010; Enomoto, Warner, \& Nygaard, 2021).

How one experiences learning is critical to the level of engagement in their learning processes. A Constructivist Theory (i.e., an experiential/active learning approach to learning) (Enomoto, Warner, \& Nygaard, 2021) has been found to elevate learning outcomes; as has active learning setting designs. Some Constructivist foundational scholars include Dewey (1938), Piaget (1971), and Vygotsky (1978). But active learning doesn't just happen. Cumulatively, it has been recognized across time, that engaging students in his/her learning processes provides for deeper, richer, more authentic learning situations (Nicaise, Gibney \& Crane, 2000). Different teaching models have been generated to help educators intentionally teach allowing the students to own their own knowledge. Such teaching models include Inquiry-, Problem-, Project-, and Phenomenal-based models (Enomoto, Warner, \& Nygaard, 2021). Each of these models expects a particular behavior from the student. The building's designs 'cue' the user in terms of the types of behaviors expected (Scott-Webber, 2004). Thus, there is a perceived connection between the design for learning, and the design of the learning place.

This study's research premise is, 'that learning should be student-centered and the design of the built space should support user needs.' It argues a true leap from 19th century practices, passive, to 21 st century ones, active, would emerge. This idea concurs with reports from the Brookings Institute and the World Development (Vegas \& Winthrup, 2020). Vegas and Winthrup argue that “...it is valuable to look beyond these immediate concerns (essential caretaking role schools play in society) to what may be possible for education on the other side of the COVID-19 pandemic... Now is the time to chart a vision for how education can emerge stronger from this global crisis than ever before (n.p.)." "The World Development Report 2018 (WDR 2018)_LEARNING to Realize Education's Promise - is the first ever devoted entirely to education. And the timing is excellent: education has long been critical to human welfare, but it is even more so in a time of rapid economic and social change. The best way to equip children and youth for the future is to place their learning at the center. The 2018 WDR explores four main themes: 1) education's promise; 2) the need to shine a light on learning; 3) how to make schools work for learners; and 4) how to make systems work for learning (World Bank Group, 2018) (underline by this author). Another touch point is shared by Vegas and Winthrup (2020) from the report from the U.S. Census Bureau, that “...during the COVID-19 school closures, 1 in 10 of the poorest children in the world's largest economy (i.e., USA) had little or no access to technology for learning."

Multiple authors have written from multiple domains on the topics of the 'learner,' and the 'learning,' but few who have connected the built space and its' design with the notion that design matters, gives behavioral cues, and therefore should be intentionally designed to support the learning process - the 'learning place' (refer back 
to Figure 1). Research over multiple years has indicated from both the students' and the educators' perspectives that the design of the school makes a significant difference relative to student academic engagement performance (Nissim, Weissblueth, Scott-Webber, \& Amar, 2016; Scott-Webber, 2014, 2019; Scott-Webber, Marini, \& Abraham, 2000; Scott-Webber, Strickland, \& Kapitula, 2013). Engagement does matter —online or onsite, thus the design of the learning place must fit these needs.

Developing future-centered education means making teaching and learning more practice-based and putting students' learning experiences first (Ruffo, 2008; Flynn \& Vredevoogd, 2010; Vegas \& Winthrup, 2020; World Bank Group, 2018). We have “...to reinforce, complement, and bring to life learning experiences in and outside the classroom. It would recognize and adapt to the learning that takes place beyond its walls" (Vegas \& Winthrup, 2020, n.p.). Teachers create that experience and the built place should support these instructional needs (Montessori, 1913; Malaguzzi, 1950-The Reggio Emilia approach). Thus, in order to understand engagement, it is perhaps telling as to what teaching model is being used. Previous research has indicated a connection between the perceived level of student engagement and the teaching model used. Were educators able to hold onto this hard-won knowledge?

This study worked to uncover whether or not it was possible to use active teaching models (see Table 1) in either situational scenario; online or onsite. If so, how were they being used, modified, or did some other method have to take their place? Although small, a 'pilot' study, it is believed that the learnings from this work are important. They reveal a situation in major flux, multiple and simultaneous issues that awakened the educational community to its lack of 21 st century preparedness for itself and its learners, some new learnings from the educators for how they might envision a post-COVID future, but few strong conclusions at this time. The research method is described next.

\section{Method}

This research used a Human-Centered Research Design (HCRD) protocol (see Figure 2). The focus of human-centered research seeks to understand how the design of the built environment impacts human behavior, importantly how users behave and if that behavior was anticipated in the development of the design solution(s). Multiple methods are often used to answer research questions, but fall into two broad areas, qualitative and quantitative. To ensure a rich set of data is generated, the HcRD protocol always uses a mixed-method (Johnson, Onwuegbuzie, \& Turner, 2007) research design (inclusive of both quantitative and qualitative techniques) for comparative purposes, and thus limits research bias, typically use the following:

1) Quantitative techniques = literature review, content analysis, and "questionnaires and surveys" (Hanington, 2010, p. 22), and

2) Qualitative techniques = "observing and talking to people...these methods are typically ethnographic in nature, and may include participant observation, artifact analysis, photo and diary studies, contextual inquiry, cultural probes, and other methods designed to sample human experience" (Hanington, 2010, p. 23 ), as well as crowd-sourced images or text; and often in naturalistic settings.
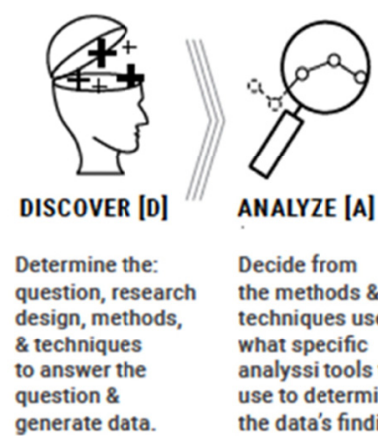

Decide from the methods \& techniques used what specific analyssi tools to use to determine the data's findings.

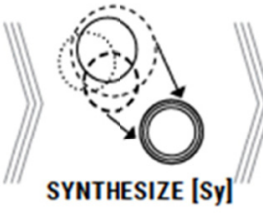

Take the information generated from the multiple analytic methods \& develop an understanding of what the findings mean

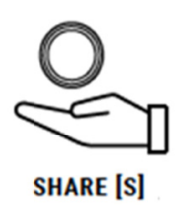

Provide multiple types of items for sharing to multiple user groups: client, designer, conference presentation, peer-reviewed journal article...

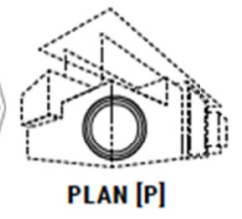

$$
\begin{aligned}
& \text { Use the "truth" } \\
& \text { from the findings } \\
& \text { to revisit the } \\
& \text { building, and/or } \\
& \text { determine what } \\
& \text { items should be } \\
& \text { incorporated into } \\
& \text { the next design. }
\end{aligned}
$$

Figure 2. A Human-centered Research Design Protocol (HcRD) [Icons developed by DLR Group for this author]

The research question ("How might educators across the K-12 spectrum envision the future of learning 
post-pandemic?"), and the research design are in harmony as the HcRD is human-centered and supports inquiry relating to how the built environment impacts human behavior. A short definition for each step in this Human-Centered Research Design protocol is shared:

- Discover [D]: Develop a research question/hypothesis and understand what will be the best research design, methods and techniques to find answers, and use them to gather data. It's best to use three techniques to ensure bias is reduced. Once gathered the researcher(s) puts this information into appropriate format(s) for analysis. Whether using quantitative methods or qualitative methods, all data will be worked to produce some numerical findings. Once this latter stage is done, these become research 'instruments' or tools. (NOTE: a human subject's protocol has been reviewed by a third party prior to beginning work with a client; all consent forms approved and received).

- Analysis [A]: Take the data from the research techniques and use appropriate methods to break down the information. By using multiple discovery techniques to avoid bias ensures the comparisons generates consistent and reliable findings. Use statistical methods when appropriate. Pilot test and test again to vet the data for reliability and validity.

- Synthesis [Sy]: Recognize the analysis phase of this work only generates facts. What these facts 'are saying,' how each is connected to the next is revealed by generating meaning and understanding relative to the original question. This segment takes time and expertise to clarify and built a 'truthful' and unbiased consensus from the data.

- Share [S]: Be prepared to share information to multiple audiences and for multiple purposes - clients, designers, conferences, and research manuscripts.

- Plan [P]: Know all data reveal a truth—not always the ones we're looking for or expecting. Be prepared to plan for next steps (ex, go back and address an issue found in a design and/or adjust the design solution for the next time it is used).

\subsection{Step-by-Step Process and Sample}

This research used 3 techniques to garner data: 1 quantitative (i.e., the survey), and 2 qualitative (i.e., interview and crowdsourced photographic traces). The step-by-step process included:

- purposefully targeting educators teaching in the K-12 cohort;

- using a convenience sample filling the following areas: all educators, teaching in grade cohorts $\mathrm{K}-5$, 6-8, and/or 9-12; a mix of public, private and charter schools across North America were invited;

- ensuring the research design and human subjects' protocol were reviewed by a third-party institutional research review firm - Heartland Institutional Review Board;

- using three specific HcRD techniques: (1) quantitative-an online survey ( $\mathrm{n}=39$ ), (2) qualitative —online interviews $(\mathrm{n}=15)$, and (3) qualitative crowd-sourced photographic traces images and viewpoints $(\mathrm{n}=30)$; overall $\mathrm{n}=84$;

- having all schools' and/or individuals' names coded to provide anonymity; and

- sharing that each participating school could elect to have their names put 'into a hat' with the opportunity to receive a Hokki stool from VS America, Inc.

This research study was conducted to hear the voices of educators relative to how the design of learning experiences, and places were at the current moment (in-pandemic), and how these might be thought of in a post-pandemic world; in the K-12 arena. We knew the world of education had been turned upside down due to the pandemic, and each school and district were facing unpresented unknowns. We also recognized that through this challenge a 'new blank canvas' could open up, with opportunities to reshape the future of education's purpose, meaning, models and how the design of learning experiences, as well as how the spatial environment might be reimagined to support educator collaboration needs (i.e., time/space, Scott-Webber, 2020a), and perhaps leave some historical practices behind.

The foci were on these view planes. What was... (1) the pre-condition, (2) the current situation, and (3) what might be designed for the future from lessons learned from both the students' learning and teachers as colleagues' perspectives. The research questions addressed these situations from Time/Space Learning Experience Continuum as seen in the matrix (see Figure 3, Scott-Webber, 2020a). Time being recognized as a continuum between synchronous and asynchronous, and Space's continuum defined as onsite to online. 


\section{TIME/SPACE LEARNING EXPERIENCE MATRIX}

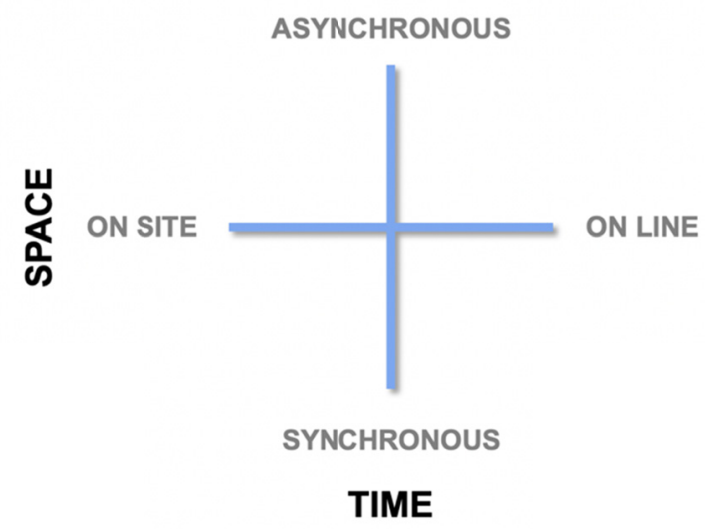

Figure 3. Time/Space Learning Experience Continuum Matrix (Scott-Webber, 2020a)

\section{Results}

As mentioned, the sample size was too small for this pilot to gather psychometric properties relative to validity and reliability for the survey instrument. A second study will commence in spring 2021 with the hopes of addressing that issue.

However, the multiple collection methods helped generate some important understandings about this unpresented point in time. It must be noted, however, it is the first time in this author's $20+$ research career that there was a wholesale push back from school district leaders across North America not allowing any connection to educators or students during the time of this study - fall 2020; due specifically to the disruption of the pandemic. Therefore, not enough data was garnered to review statistically. All survey responses were tallied using SurveyMonkey's quantitative analytics program. The results section will provide findings organized by:

- Data by technique - survey, interviews and crowd-sourced; and

- Data as it relates to the Time/Space Learning Experience continuum.

\subsection{Data by Technique}

There were three techniques employed in this HcRD research design: (1) an online survey, (2) online focused interviews by school, and (3) crowd-sourced photographic trace images and remarks from one FaceBook source based on questions relative to this research. This section will share information from each. A summary will follow.

\subsubsection{Online Survey}

Using educators as learning experts, we asked them the following...

- Thinking of a "future-focused" learning place...

- How might you envision such a place where all learners (students \& educators) thrive?

- How is the emphasis on authentic, deep, learning experiences changed?

- How do these types of learning experiences change for on-line vs. in-place?

- What types of interactions between educators will be (a) new, (b) enhanced, (c) re-imagined, and (d) deemed necessary?

- How might the built environment be re-imagined to support the 'all learners thrive' goal?

- What spaces work now? Don't? Are needed, but don't have?

O Other ideas?

There is a mix of educators from the various grade cohorts: K-5, 6-8, and 9-12. Two countries were represented-USA (55\%) and Canada (45\%), along with institutional setting types; at almost a 50/50\% it was elected not to try and draw differences for this pilot. Several demographic data points are worth sharing. Most 
educators had been teaching for over 11+ years. Figure 4 (see Figure 4) shares the information about the cohorts' taught, and Figure 5 (see Figure 5) indicates the type of educational institutional settings.

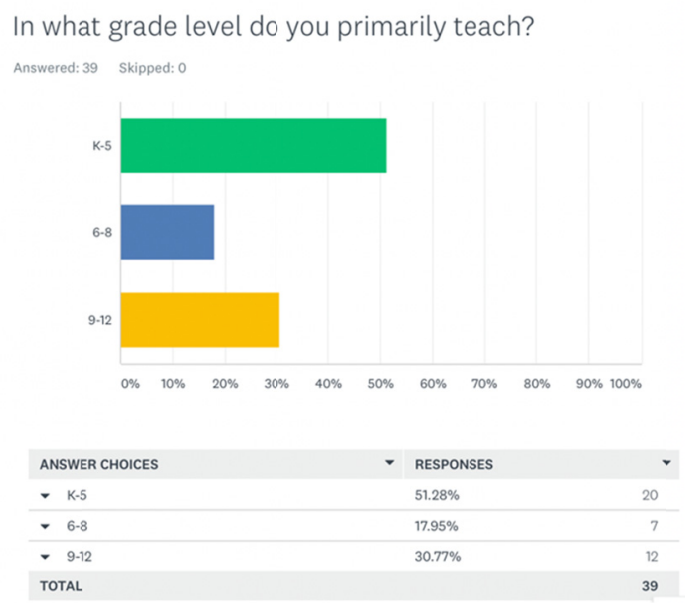

Figure 4. Grade levels taught

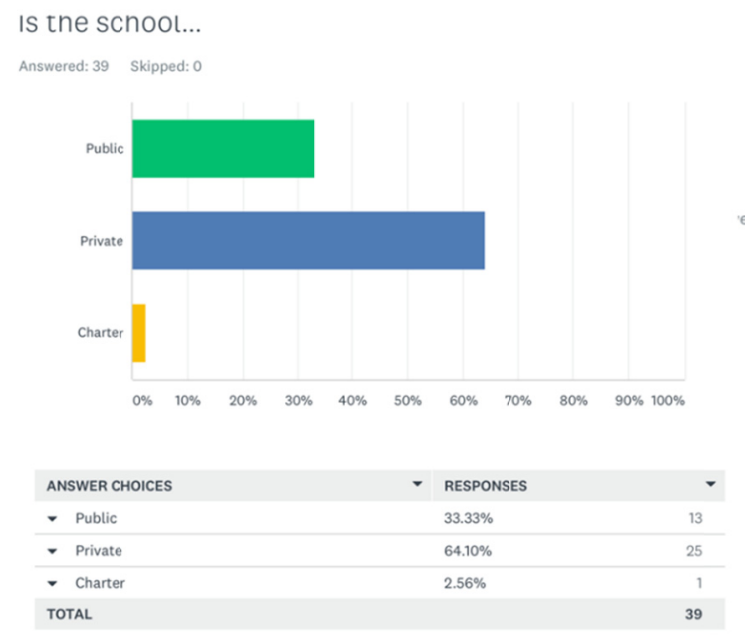

Figure 5. Type of institutional setting

The online survey began by setting up the situation. It asked: "We want to ask you about the Instructional Models and Teaching Practices you utilize most often. Think about these questions in three different ways: (1) Pre-pandemic, (2) Current-pandemic, and (3) Post-pandemic (Or, what would you most desire as a change for the future of education?)" (see Table 1). 
Table 1. Teaching models: Pre-, current- and post-pandemic used most often [choose 2]

\begin{tabular}{lllll}
\hline Teaching Model & Pre-pandemic & Current-pandemic & Post-pandemic Goal & Total Respondents \\
\hline Problem-based & $57.69 \%$ & $69.23 \%$ & $53.85 \%$ & \\
& 15 & 18 & 14 & 26 \\
Project-based & $85-29 \%$ & $64.71 \%$ & $64.71 \%$ & 34 \\
Inquiry-based & 29 & 22 & 22 & \\
& $72.22 \%$ & $77.78 \%$ & $72.22 \%$ & 36 \\
Personalized learning & 26 & 28 & 26 & \\
& $72.41 \%$ & $75.86 \%$ & $65.52 \%$ & 29 \\
Lecture-based & 21 & 22 & 19 & \\
& $44.44 \%$ & $88.89 \%$ & $33.33 \%$ & 18 \\
Flipped-based & 8 & 16 & 6 & \\
& $27.78 \%$ & $72.22 \%$ & $55.56 \%$ & 18 \\
Other & 5 & 13 & 10 & \\
& $66.67 \%$ & $66.67 \%$ & $33.33 \%$ & 6 \\
\hline
\end{tabular}

To drill down further from teaching models into the teaching practices, Table 2 provides more insights (see Table 2).

Table 2. Teaching Practices Incorporated Most Often [choose 3]

\begin{tabular}{|c|c|c|c|c|}
\hline Teaching Practices & Pre-pandemic & Current-pandemic & $\begin{array}{l}\text { Post-pandemic } \\
\text { Goal }\end{array}$ & $\begin{array}{l}\text { Total } \\
\text { Respondents }\end{array}$ \\
\hline \multirow[t]{2}{*}{ You lecture, \& students listen $\&$ take notes } & $68.42 \%$ & $78.95 \%$ & $21.05 \%$ & \\
\hline & 13 & 15 & 4 & 19 \\
\hline \multirow[t]{2}{*}{ You lead discussion with student responses } & $82.86 \%$ & $97.14 \%$ & $62.86 \%$ & \\
\hline & 29 & 34 & 22 & 35 \\
\hline \multirow{2}{*}{$\begin{array}{l}\text { You launch a project } \& \text { students move into } \\
\text { small-group work }\end{array}$} & $87.50 \%$ & $71.88 \%$ & $65.63 \%$ & \\
\hline & 28 & 23 & 21 & 32 \\
\hline You get students started \& then they work & $82.14 \%$ & $53.57 \%$ & $64.99 \%$ & \\
\hline $\begin{array}{l}\text { together over a longer time frame [EX: team } \\
\text { project] }\end{array}$ & 23 & 15 & 18 & 26 \\
\hline Students make things in class with their hands & $85.29 \%$ & $52.54 \%$ & $70.59 \%$ & \\
\hline [EX: hands-on activities] & 29 & 18 & 24 & 34 \\
\hline You provide opportunities for real-world & $82.36 \%$ & $79.41 \%$ & $73.53 \%$ & \\
\hline applications & 28 & 27 & 25 & 34 \\
\hline Student initiates independent or group work while & $80.65 \%$ & $67.74 \%$ & $70.97 \%$ & \\
\hline you facilitate \& check on student progress & 25 & 21 & 22 & 31 \\
\hline Students work independently on education & $48.26 \%$ & 93.105 & $48 / 28 \%$ & \\
\hline apps/websites & 14 & 27 & 14 & 29 \\
\hline Students independently read texts followed by & $61.90 \%$ & $95.24 \%$ & $42.86 \%$ & \\
\hline worksheet activity & 13 & 20 & 9 & 21 \\
\hline
\end{tabular}

It is also recognized that teachers may often teach alone, but typically they do not work alone. Many items related to the 'work of pedagogy' (Scott-Webber, 2020b) relating to curriculum development, assessment, preparation and service to the community among items often shared. This next question asks how the teachers work with their colleagues now, and how they might envision in the future what that connection to others could look (see Table 3). The reasons these questions are important gets back to Maslow's Theory (1943) and a needed sense of belonging in order to thrive. 
Table 3. How you and your teaching colleagues work together

\begin{tabular}{|c|c|c|c|c|}
\hline Working with Colleagues & Pre-pandemic & Current-pandemic & $\begin{array}{l}\text { Post-pandemic } \\
\text { Goal }\end{array}$ & $\begin{array}{l}\text { Total } \\
\text { Respondents }\end{array}$ \\
\hline \multirow[t]{2}{*}{ Independently of each other all of the time } & $42.86 \%$ & $95.24 \%$ & $28.57 \%$ & \\
\hline & 9 & 20 & 6 & 21 \\
\hline \multirow{2}{*}{$\begin{array}{l}\text { Collaboratively on developing assignments some } \\
\text { of the time }\end{array}$} & $85.71 \%$ & $60.71 \%$ & $53.57 \%$ & \\
\hline & 24 & 17 & 15 & 28 \\
\hline \multirow{2}{*}{$\begin{array}{l}\text { Collaboratively on developing assignments all of } \\
\text { the time }\end{array}$} & $62.50 \%$ & $81.25 \%$ & $50.00 \%$ & \\
\hline & 10 & 13 & 8 & 16 \\
\hline \multirow{2}{*}{$\begin{array}{l}\text { Collaboratively only on items for the school's } \\
\text { and/or department's overall curricula and/or } \\
\text { service needs }\end{array}$} & $73.91 \%$ & $73.91 \%$ & $47.83 \%$ & \\
\hline & 17 & 17 & 11 & 23 \\
\hline \multirow[t]{2}{*}{ At the same time in the same space } & $76.19 \%$ & $52.38 \%$ & $57.14 \%$ & \\
\hline & 16 & 11 & 12 & 21 \\
\hline \multirow[t]{2}{*}{ At different times in different spaces } & $45.83 \%$ & $79.17 \%$ & $45.83 \%$ & \\
\hline & 11 & 19 & 11 & 24 \\
\hline
\end{tabular}

The next segment of the questionnaire sought to understand within which part of the school building did the educators do most of their teaching in the pre-pandemic only situation? As seen in the next figure (see Figure 6), the dominant teaching place is 'my classroom'. When one does not 'own' one's own classroom, or learning place, the question then becomes, "Where do you keep all of your personal/professional belongings?" The responses to the ' $b$ ' and ' $c$ ' segments of the last question are shared next in Figure 7 (see Figure 7); 10\% of respondents answered the latter.

Would you say your primary teaching [i.e. classroom/learning place] area was...

Answered: 39 Skipped: 0
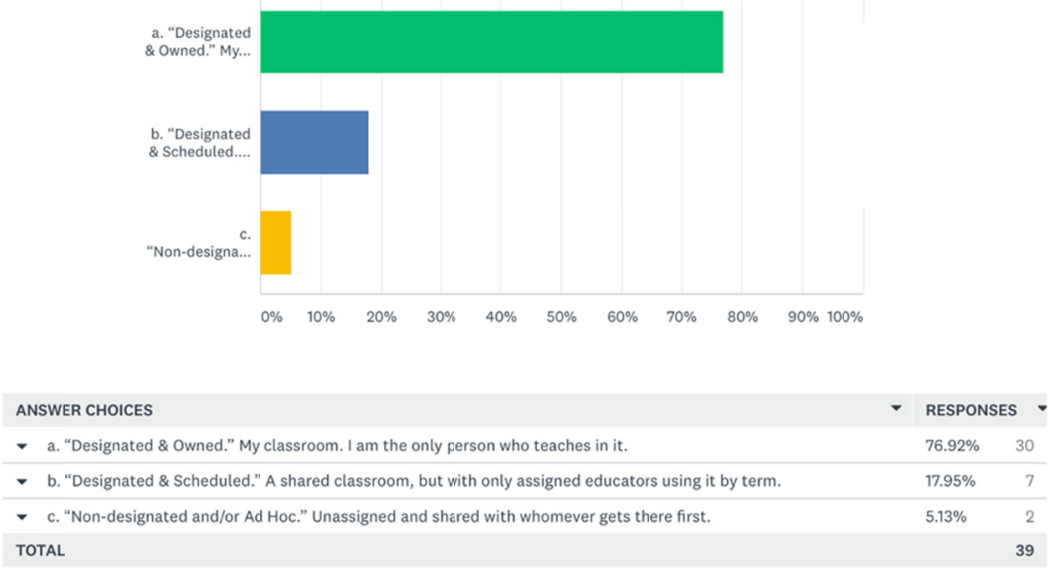

Figure 6. Where is your primary teaching place-pre-pandemic? 
If you answered 'b' or 'c' from question 10, where did you keep all of your professional/personal belongings? You had an...

Answered: 10 Skipped: 29

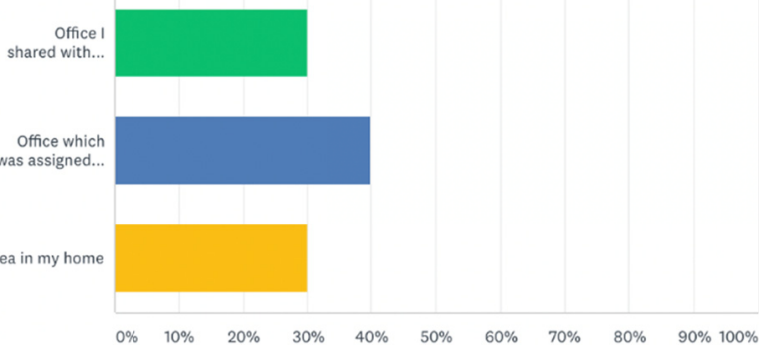

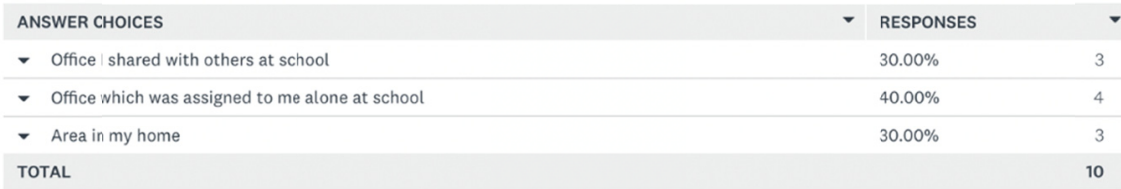

Figure 7. When you don't 'own' your own classroom, where do you keep your belongings_-pre-pandemic?

The last segment of the questionnaire asked educators to think using a 'future-focused' scenario. It asked them to express their ideas on what learning and teaching experiences should emerge using this new blank slate (i.e., lessons learned during COVID-19); incorporating all that has been learned about learning from learning/cognitive sciences, social and emotional wellbeing needs, personalized learning, and the ability to thrive as educational professionals (see Figure 8). It's obvious here. Teacher's want to stay in their comfort zone-my classroom/my way. But there is a little movement into thinking about using technology as synchronous or asynchronous in combination with onsite time.

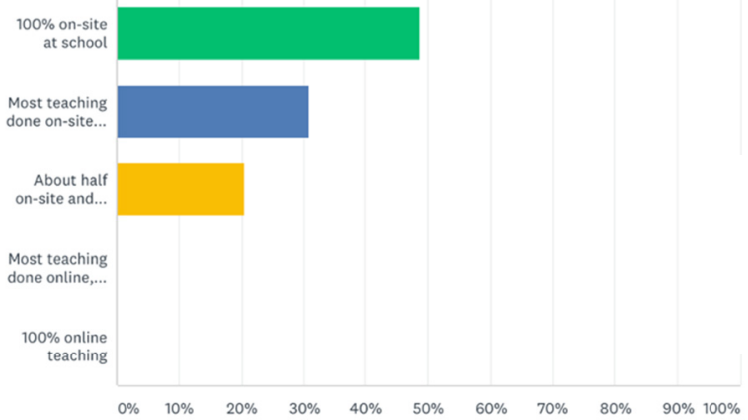

\begin{tabular}{|c|c|c|}
\hline ANSWER CHOICES & RESPONSES & - \\
\hline - $100 \%$ on-site at school & $48.72 \%$ & 9 \\
\hline - Most teaching done on-site at school & $30.77 \%$ & 12 \\
\hline About half on-site and half virtual & $20.51 \%$ & 8 \\
\hline - Most teaching done online, with some on-site & $0.00 \%$ & 0 \\
\hline $100 \%$ online teaching & $0.00 \%$ & 0 \\
\hline TOTAL & & 39 \\
\hline
\end{tabular}

Figure 8. Where is the learning place of the future?

There was a comment section provided in the online survey as well. These are provided in bullet points featuring comments said more than one time. 
- Continue the partnership with the parents online

- Make teaching authentic

- No more standardized testing

- Integrate personalized-, problem-, and project-based learning

- Provide hands-on and team work

- Get students out into the community—real world

- More teachers will be trying the flipped-classroom style

- Have fully designated virtual teachers and the opposite

- Teaching would be blended

- Enriched virtual experience

- Relationship based with tech used to facilitate mentorships and experiential learning

- Forced to re-think teaching and learning.

A Summary

Teaching models and practices provide the opportunities for active learning. Using just one example of the self-reporting information, it was indicated that in the pre- and post-COVID world they did and would continue to use an Inquiry-based teaching model (ex: $72.22 \%$ ); this model got 36 votes (each person could vote for only two models used most). This type of active model requires students to be highly engaged in their learning processes as it is student-focused. During the pandemic teachers even suggested they used this model even more- $77.78 \%$ (refer back to Table 1). However, their response to teaching practices doesn't seem to hold this student-focused, Inquiry-based model's philosophic approach to learning when we see the following teaching practices actually incorporated. Items from Table 2 (refer back to Table 2) are repeated here in bold for emphasis (see Table 4); a disturbing connection.

Table 4. Teaching practices Miss Aligned with inquiry-based model—self reported (choose 3)

\begin{tabular}{|c|c|c|c|c|}
\hline Teaching Practices & Pre-pandemic & Current-pandemic & Post-pandemic Goal & Total Respondents \\
\hline \multirow[t]{2}{*}{ You lecture, \& students listen $\&$ take notes } & $68.42 \%$ & $78.95 \%$ & $21.05 \%$ & \\
\hline & 13 & 15 & 4 & 19 \\
\hline \multirow[t]{2}{*}{ You lead discussion with student responses } & $82.86 \%$ & $97.14 \%$ & $62.86 \%$ & \\
\hline & 29 & 34 & 22 & 35 \\
\hline Students work independently on education & $48.26 \%$ & 93.105 & $48 / 28 \%$ & \\
\hline apps/websites & 14 & 27 & 14 & 29 \\
\hline Students independently read texts followed & $61.90 \%$ & $95.24 \%$ & $42.86 \%$ & \\
\hline by worksheet activity & 13 & 20 & 9 & 21 \\
\hline
\end{tabular}

Note. Items are highlighted to show the differences.

From the Time/Space Learning Experience continuum, it appears that teachers will continue to envision a world much like what they have now - in 'my classroom' and onsite. There were some that saw adding an online component would be important, but it didn't seem to make the big leap to a full FLIP learning experience for students - using the best of online and the best of onsite whether synchronous or asynchronous modes.

\subsubsection{Online Focused Interviews}

Only two schools chose to participate in the interview segment, one from the USA and one from Canada. The following represents the highlights of these conversations that were transcribed from the recorded interviews. All interviewees names and school names remain anonymous. The interviews began by sharing the research protocols. The introduction, "On one level, education has a new 'blank slate.' Given all we know scientifically about how individuals learn [e.g., cognitive neuroscience, learning science, social and emotional wellbeing and active engagement], we'll be asking for your expertise to tell us what this post-pandemic, reimagined learning world should ideally look like".

These were the eight questions:

1) In a 'new normal', what guides you relative to the learning experiences of the student? Is it ...

a. Using teaching models promoting Inquiry-, Problem-, Project-based learning objectives? 
b. Developing a hybrid/blended learning strategy [online and onsite] as a standard strategy?

c. Keeping the same approach as I have in the past.

2) How might you envision the future of learning for this age cohort post C-19? [different/same]

3) Do you believe there will be an ongoing need for a blended learning experience? [\%]

4) How might the current spatial environment you are in change to support your vision? [needed, missing, should go away]

5) What types of opportunities will you have to work collaboratively with colleagues? [different/same]

6) What types of physical spatial needs would you need to support these collaborative efforts?

7) What roles do you see parents take on in the learning of their child?

8) Other?

It was important to understand whether these schools were online, onsite or a hybrid of the two. The Canadian school was $100 \%$ online at the time of the interview, and the USA one $100 \%$ onsite, with a soon to move to a new hybrid situation (i.e., some days totally online and alternating days smaller groups onsite).

Some real challenges emerged in the discussion from question \#1. These were shared across the two schools and included:

- A worry that online and onsite student were apart physically and not able to collaborate easily.

- Teaching strategies have moved to more didactic rather than collaborative connections.

- No one wants to share alone out loud. They are/were ok in small groups.

- Always seem to have technology issues.

- No professional development support offered.

- They can't physically move. Sitting in one place is not good for children.

- Onsite we have physical tape restrictions, plexiglass, no 'turn and talk', masks cancel hearing, etc. etc.

One quote sums the feelings up, and we just got started, "I feel sad. It feels like I am in a box and like I have gone back to a teaching style I never wanted to ever do."

Experiences that forced schools to go completely online, and even those getting ready to go online, have insights about some consequences for the future. A few teachers feel that a component of online learning should be part of the ongoing learning experience moving forward. There were definitely digital literacy issues relative to both the educators and the students, and opportunities for correcting these should be made a part of everyone's educational norm. Even though equity issues were brought about due to lack of internet or access to computers, teachers in this conversation recognized the benefits of the FLIP (i.e., lecture goes home, and homework comes to the classroom) as beneficial (once students and educators are well versed in the method) to actually support more personalized learning and modify equity issues. There was a belief that this situation would be 'their new normal' for the near future. There was also an acknowledgement that many families were struggling — struggling to keep up with children's learning needs, sharing computers and internet, and trying to keep working.

Once past the digital divide, educators actually wanted more enriched experiences for online learning, and robust infrastructures for all. These ideas included using Augmented Reality, the use of Artificial Intelligence, and adding gamification of education into the mix. The online sessions provide a useful record of lessons and planning. Engagement is critical and finding ways to connect is worth investigating.

For the onsite situation special issues come to mind:

- Janitorial duties not just at the end of the day, but between classes; setting and re-setting classes

- 19th century physical set up with row-by-column seating and all eyes forward to meet the Center for Disease Control's specifications [USA only]

- We need to go outside more

- Training, training and more training

- Furnishing that are agile are critical to support what we need to do, and do quickly.

A second segment of the interview delved into the idea that educators often work together supporting the multiple aspects of 'the work of pedagogy.' It is believed, therefore, that for educators to thrive, it is important 
for them to be able to collaborate with each other. Questions 5 and 6 addressed this perceived need. Some insights included:

- Teaching alone and in co-teaching scenarios already exist and imagine they will stay

- Have some mentors and recognized they really need them now-"my lifeline; emotionally and professionally!"

- It's been a huge learning curve to try and go online, and IT staff have been really supportive

- Had to do most of my IT learning by myself.

In question 6 , it asks educators to think more broadly about what the design of a physical space might afford once onsite teaching becomes more of a reality. Here is what they shared:

- We are too siloed when teaching in 'my' space; but need a 'non-threatening' space for us to connect

- Walls to write upon and to have professional development sessions

- Too many spaces that don't really have a purpose

- Place to 'plug and play'

- Show the learning, and a place where we can think out loud

- All circular tables for real collaboration

- Why can we have a place where we can go outside?

It was also asked, what else might you add? Table 4 (see Table 4) shares these thoughts. But in essence becomes the summary of the interviews.

Table 4. What else?

\begin{tabular}{ll}
\hline Canada School & USA School \\
\hline$\circ$ Tools are soooo important & $\circ$ Distance learning means we are still connected and united \\
$\circ$ Technology but also analogue tools & $\circ$ Want the same experience and relationship as we have in class and \\
that is harder to do online - something I am worried about. \\
$\circ$ Operating systems; learning management systems & $\circ$ Want to believe 'this' is temporary \\
$\circ$ Tech support as many times it doesn't work or goes down & $\circ$ Want to not have to wear masks as none of us hear the other person \\
$\circ$ Make sure everyone is trained - more Pro D & as well - clarity is compromised \\
$\circ$ Foundation support & $\circ$ Students are not receiving 21st century learning \\
$\circ$ Training & $\circ$ Get rid of: large class sizes, sitting in a class all day, row and \\
$\circ$ Laptop karts - computers are out dated and kids are at different & column arrangements \\
levels of proficiency / so are teachers & $\circ$ Keep: teacher as facilitator [combining online and onsite]; \\
$\circ$ Independent school and recognize we have a lot & collaboration for students and educators; keep it AWESOME; make \\
$\circ$ Equality of education for all is the dream & places flexible so we can move things completely out of the way \\
$\circ$ Comfy seating/plop down areas; support changes of postures; agile & $\circ$ Keep moving outside for students and teachers \\
$\circ$ Flexible seating; I go to garage sales to find these - can't have & $\circ$ Make sure to have movement if on IT \\
fabric due to cleaning needs & \\
$\circ$ Standing desks/ stools & \\
$\circ$ Wipe down easy surfaces & \\
$\circ$ Breakout areas; practice areas; thinking areas & \\
\hline
\end{tabular}

\subsubsection{Crowd-Sources Photographic Trace Images and Remarks}

The crowd-sourced information came from Trevor Muir's FaceBook followers. Thanks again Trevor. The purpose here was to 'get a glimpse' of what these situational learning places looked like during this pandemic time; as no one was allowed into the schools. Mr. Muir started with a prompt (see Figure 9). The research protocols were shared and instructions specifically indicated no pictures of people in these photos; a photographic trace, ethnographic technique (Zeisel, 1991). It was also requested that the responders feel free to share their day-to-day situation. This section will start with an array of pictures (screen shots were taken so as not to include the responder's information), and then the transcribed information as sent by responders (see Table 5). 


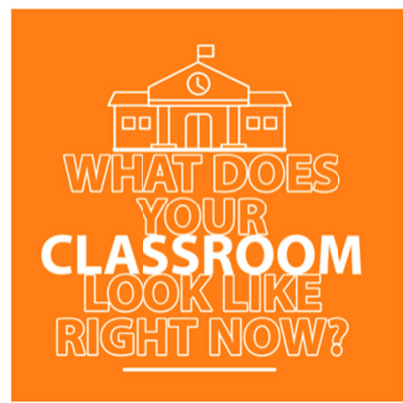

Figure 9. What does your classroom look like right now? (crowd-sourced data from T. Muir, 2020)

Table 5. What does your classroom look like right now? (A sample)

\begin{tabular}{|c|c|c|}
\hline $\begin{array}{l}\text { Very different, I am split between } 2 \\
\text { rooms and it is very plain. Not } \\
\text { allowed bookshelves and very ittle } \\
\text { surface space. }\end{array}$ & 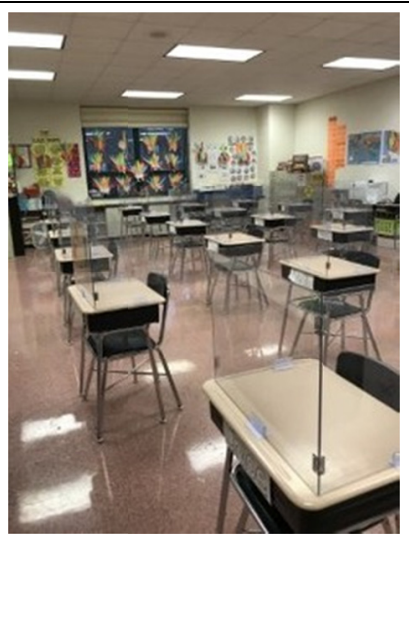 & 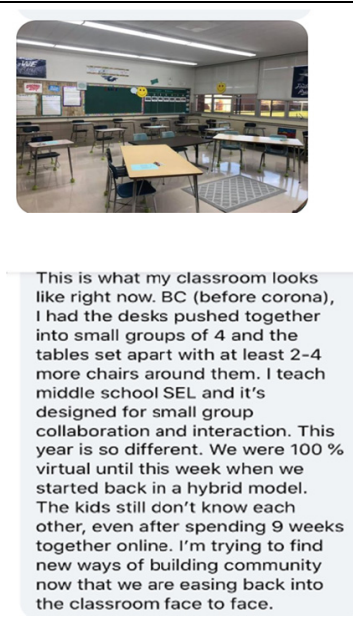 \\
\hline 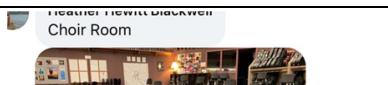 & & fyon \\
\hline Ný sth grade english 1 classroom! & 5ith grade & 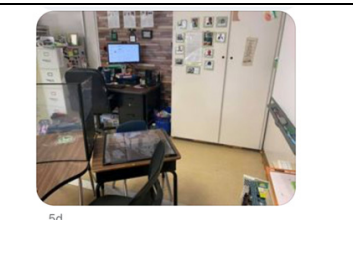 \\
\hline 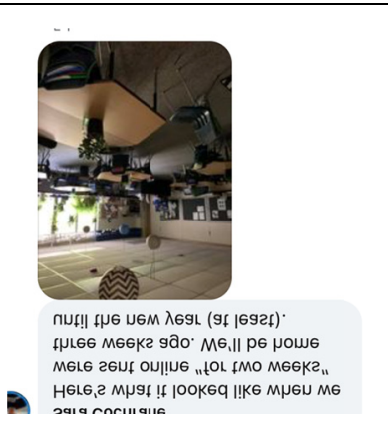 & 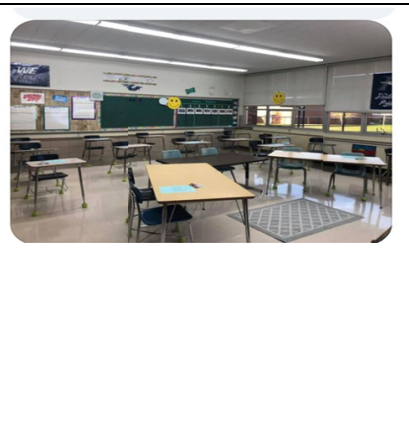 & My "classroom" is in my bedroom. \\
\hline
\end{tabular}




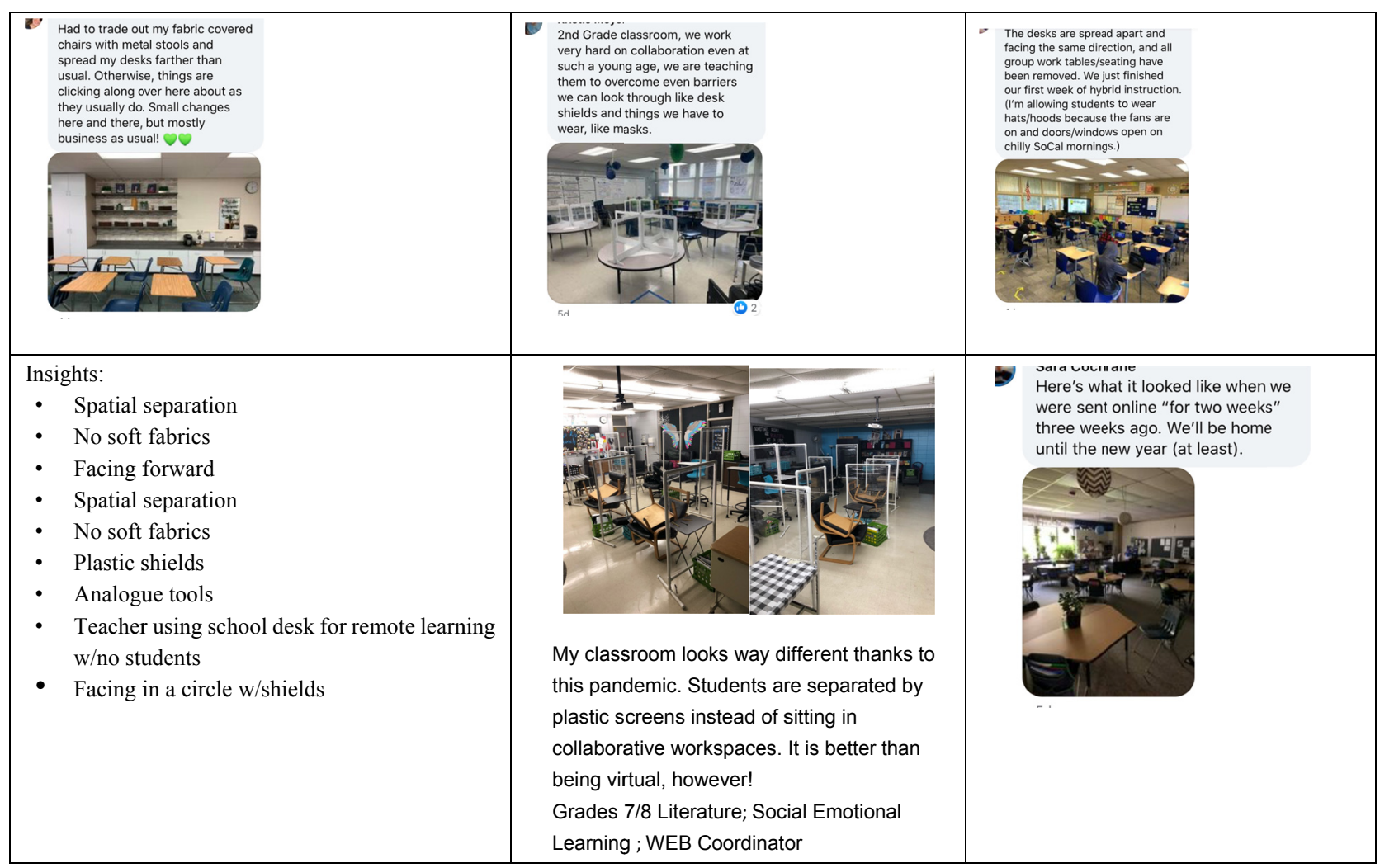

Responders were mixed across the teaching spectrum, however there was no way to identify country of origin unless it was shared in the post. Insights are shared in Table 5 (refer back to Table 5). Some hopes and dreams were also expressed. These offer a summary:

- "After this is all said and done, I hope folks look to continue building relationships with kids, their families and their colleagues. I hope they continue to look for ways to engage their kids without using technology all of the time. I hope they go back to collaboration and conversation.

- I hope the world becomes a kinder more tolerant place. I hope that teachers focus on helping kids "be good people" and work on teaching "thinking skills and real world" rather than old school teaching.

- The world needs to be inspired by people like you who speak the truth, speak your mind and help teachers become not only better teachers, but better humans!"

\section{Conclusion}

2020 was a historic time in the field of education. Thus, it was important to try and capture the moment. This research was scaled back, not due to the researcher's change, but for the fact that schools and districts would not allow anyone to connect with their educators or their students due to the pandemic situation and their perceived chaos that ruled. Although small, it is argued here that the moments captured by using a triangulate method and three data collection techniques, provide some useful insights into the pre-, current-, and post-pandemic scenarios; and this view of pre-, current-, and post-pandemic scenarios sets this research apart. The grade cohorts ranged from K-12 teachers, and were from two countries (USA and Canada) as a convenience sample.

Active learning, and the authenticity it provides for learners, is not easy to deliver. When a major disruption occurs and opens up the realization that the 21 st century educator and student are facing a major digital divide. The teaching practices pre-pandemic did not include online learning, nor did it seem that educators realized its value. Come current-pandemic, a big majority of schools were plunged into this online world without the knowledge it takes to prepare, deliver and assess - “....more training, more training, more training!" The online learning was often same time/different place or synchronously delivered. The onsite situations differed, but most had to prepare classrooms back into a 19th century layout of row-by-column seating with eyes forward and teaching from the front. Plexiglass barriers, wiping down of furnishings, and pod-like connections to students seem to be one option. Another option for the onsite and online was a new hybrid. Some classes taught synchronously online on certain days, while on alternating days students would be in smaller pods and 
onsite - still synchronously. The only asynchronous items indicated were what were listed in the teaching practices including: students working independently on education apps/websites, and students independently read texts followed by a worksheet activity. The Time/Space Educational Experience Continuum was not easy to pin point. This sample seemed to be mostly in the online or onsite/synchronous sector.

There are some important implications to consider for future learning experiences:

- Recognize there is a major digital divide across North America, and it impacts both educators and students;

- Teach teachers how to embrace 21 st century practices using time-honored teaching models is necessary;

- Demand for a portion of the hybrid, FLIP, or Blended learning practices perhaps should be here/will be here to stay given the uncertainty of the pandemic;

- Teach students how to navigate in a digital world preparing them for their future needs;

- Remember whether online or onsite, student engagement in an authentic way is critical for their learning progress and technology and spatial designs play important roles here; and

- Keep a future-focused view plane in place for active learning, remembering all we know about how we actually learn.

Alignment of deep, authentic learning, teaching models/practices, delivery setting (i.e., online or onsite), and how each delivery setting is actually designed are all necessary; intentional planning will provide appropriate outcomes. Maybe even the ones we all reach for with a future-focused agenda. One teacher's summary, "Please don't send me back to a world I never wanted to be in with rows-and-columns, and me at the front."

\section{Acknolwedgements}

With thanks to the research sponsors - VS America, Inc.

Thanks also to Trevor Muir and his FaceBook connections for the crowdsourcing data received.

\section{References}

Anderson, L. W., \& Krathwohl, D. (Eds.). (2001). A taxonomy for learning, teaching, and assessing: A revision of Bloom's taxonomy of educational objectives. New York: Longman.

Carroll, J. B. (1963). A model of school learning. Teachers College Record, 64(8), 723-733.

Dewey, J. (1938). Experience and education. New York: Macmillan.

Elliot, A. J., \& Covington, M. V. (2001). Approach and avoidance motivation. Educational Psychology Review, 13(2), 73-92. https://doi.org/10.1023/A:1009009018235

Enomoto, K., Warner, R., \& Nygaard, C. (Eds.) (2021). Teaching and Learning Innovations in Higher Education. Oxfordshire, UK: Libri Publishing Ltd.

Flynn, W. J., \& Vredevoogd, J. (2010). The future of learning: 12 views on emerging trends in higher education. Planning for Higher Education, 38(2), 5-10.

French, R., Scott-Webber, L., \& Sivakumar, A. J. (2020). Transforming the kindergarten experience by design: A comparative research case study. Journal of Education and Learning, 9(2), 83-103. ISSN 1927-5250 E-ISSN 1927-5269. https://doi.org/10.5539/jel.v9n2p82

Hall. E. T. (1966). The hidden dimension. New York, Doubleday.

Hanington, B. M. (2010). Massachusetts Institute of Technology Design Issues, 26(3), 22. Retrieved August 13, 2019

from https://s3.amazonaws.com/academia.edu.documents/31490953/DESI2603_Hanington_pp018-pp026_v4.pdf ?response-contentdisposition $=$ inline $\% 3 \mathrm{~B} \% 20$ filename\%3DRelevant_and_Rigorous_Human-Centered_Res .pdf\&X-Amz-Algorithm=AWS4-HMAC-SHA256\&X-Amz-Credential=AKIAIWOWYYGZ2Y53UL $\overline{3}$ A \% 2F20190813\%2Fus-east-1\%2Fs3\%2Faws4_request\&X-Amz-Date=20190813T185400Z\&X-Amz-Expires= $3600 \& X-A m z-S i g n e d H e a d e r s=h o s t \& X-A m z-S i g n a t u r e=73057 d c 18 \mathrm{edb} 4 \mathrm{~d} 8951 \mathrm{f} 04 \mathrm{~d} 7 \mathrm{c} 8722947 \mathrm{fae} 5 \mathrm{f39e25b}$ be6020811d68c9eff48b56

Johnson, B. R., Onwuegbuzie, A. J., \& Turner, L. A. (2007). Toward a definition of mixed methods research. Journal of Mixed Methods Research, 1, 112-133. https://doi.org/10.1177/1558689806298224

Kilbourne, J., Scott-Webber, L., \& Kapitula, L. R. (2017). An activity-permissible classroom: Impacts of an evidence-based design solution on student engagement and movement in an elementary school classroom. 
Children, Youth and Environments, 27(1), 112-134. https://doi.org/10.7721/chilyoutenvi.27.1.0112

Malaguzzi, L. (1950). The Reggio Emilia approach. The Laurel School. MA: Brewster.

Maslow, A. H. (1943). A theory of human motivation. Psychological Review, 50(4), 370-396. https://doi.org/10.1037/h0054346

Merrill, M. D. (2002). First Principles of Instruction. Educational Technology Research and Development, 50(3), 43-59. https://doi.org/10.1007/BF02505024

Montessori, M. (1913). Pedagogical anthropology. New York, N.Y. Frederick A. Stokes Company.

Nicaise, M., Gibney, T., \& Crane, M. (2000). Toward an understanding of authentic learning: Student perceptions of an authentic classroom. Journal of Science Education and Technology, 9, 79-94. https://doi.org/10.1023/A:1009477008671

Nissim, Y., Weissblueth, E., Scott-Webber, L., \& Amar, S. (2016). The effect of a new stimulating learning environment on pre-service teachers' motivation and 21 st century skills. Journal of Education and Learning, 5(3), 29-39. https://doi.org/10.5539/jel.v5n3p29

NSSE. (2010). Working with NSSE-data: A facilitator's guide. National Survey of Student Engagement, 2. Retrieved from https://nsse.indiana.edu/nsse/working-with-nsse-data/nsse-data-users-guide-with-worksheets/index.html

$\begin{array}{llll}\text { Oregon } & \text { State. } & \text { (n.d.). } & \text { Retrieved }\end{array}$ https://ecampus.oregonstate.edu/faculty/development/Active\%20Learning\%20V2.pdf

Piaget, J. (1971). The theory of stages in cognitive development. In D. R. Green, M. P. Ford \& G. B. Flamer (Eds.), Measurement and Piaget. McGraw-Hill.

Ruffo, J. A. (2008). Millennial or net generation students and their impact on the development of student-centered facilities. Planning for Higher Education, 37(1), 5-6.

Scott-Webber, L. (1999, March 22-23). Space matters-making instructional space fit user needs. IT 99, Instructional Technology Conference: The new millennium. Blacksburg, VA.

Scott-Webber, L. (2004). In-sync - Environmental behavior research and the design of learning spaces. MI: The Society for College and University Planning. Retrieved from http://books.google.com/books/about/In_Sync.html?id=snRPAAAAMAAJ

Scott-Webber, L. (2014). The perfect storm: Education's immediate challenges. In L. Scott-Webber, J. Branch, P. Bartholomew \& C. Nygaard (Eds.), Learning Space Design in Higher education (pp. 151-168). Oxfordshire, UK: Libri Publishing Ltd.

Scott-Webber, L. (2019). Rethinking spatial designs to support learning. Cracking the cover: The school campus as a 3D textbook. WI: Green Schools Catalyst Quarterly, 28-39.

Scott-Webber, L. (2020a). Time/Space Learning Experience Matrix. Dialogues.

Scott-Webber, L. (2020b). What design forgot? What happens when 'my classroom' goes away? EdSpaces Conference presentation.

Scott-Webber, L., Konyndyk, R., \& Denison, M. (2019). POE: Understanding innovative learning places and their impact on student academic engagement-index 6-8 'alpha' survey developments. Journal of Education and Learning, 8(5), 31-56. https://doi.org/10.5539/jel.v8n5p31

Scott-Webber, L. Konyndyk, R., \& French, R. (2019). Developing instruments: Student academic engagement levels and satisfaction with school design. European Scientific Journal, 15(1), 325-347. https://doi.org/10.19044/esj.2019.v15n1

Scott-Webber, L., Konyndyk, R., French, R., \& French, J. (2018). Significant results: Space makes a difference for student academic engagement levels. European Scientific Journal, 14(16), 1857-1874. https://doi.org/10.19044/esj.2018.v14n16p61

Scott-Webber, L., Konyndyk, R., French, R., Lembke, J., \& Kinney, T. (2017). Spatial design makes a difference in student academic engagement levels: A pilot study for grades 9-12. European Scientific Journal, 13(16), 5-18. ISSN: 1857-7881 https://doi.org/10.19044/esj.2017.v13n16p5

Scott-Webber, L., Loeffelman, P., Runyan, D., \& Denison, M. (2021). Is higher education ready for the transformed learner coming from 9-12? A case study. In K. Enomoto, R. Warner \& C. Nygaard (Eds.), 
Teaching and Learning Innovations in Higher Education. Oxfordshire, UK: Libri Publishing Ltd.

Scott-Webber, L., Marini, M., \& Abraham, J. (Spring, 2000). Higher education classrooms fail to meet needs of faculty and students. Journal of Interior Design, 26(1), 16-34. https://doi.org/10.1111/j.1939-1668.2000.tb00356.x

Scott-Webber, L., Strickland, A., \& Kapitula, L. (2013). Built environments impact behaviors | Results of an AL-POE. Planning for Higher Education Journal, 31(2), 16-34.

Skinner, B. F. (1974). About behaviorism. New York: Knopf [distributed by Random House].

Sommer, R. (1969). Personal space. The behavioral basis of design. Prentice-Hall, Inc., Englewood Cliffs, New Jersey.

Steelcase. (2019). Exploring innovations at work. The science of collaboration, Steelcase 360, 16. Steelcase, Inc.

Vegas, E., \& Winthrop, R. (2020). Beyond reopening schools: How education can emerge stronger than before COVID-19. Brookings Institute. Retrieved from https://www.brookings.edu/research/beyond-reopening-schools-how-education-can-emerge-stronger-than-b efore-covid-19/

Vygotsky, L. S. (1978). Mind in society: The development of higher psychological processes. London: Harvard University Press.

World Bank Group. (2018). The World Development Report 2018 (WDR 2018)—LEARNING to Realize Education's Promise. Retrieved from https://www.worldbank.org/en/publication/wdr2018

Zeisel, J. (1991). Inquiry by design. Tools for environment-behavior research. UK: Cambridge University Press.

\section{Copyrights}

Copyright for this article is retained by the author, with first publication rights granted to the journal.

This is an open-access article distributed under the terms and conditions of the Creative Commons Attribution license (http://creativecommons.org/licenses/by/4.0/). 